\title{
Understanding the Implications of Migrant Retail Trading in Ghana: A Stakeholder Perspective
}

\author{
Elijah Yendaw \\ Department of Governance and Development Management, \\ University for Development Studies, Wa Campus, Ghana \\ DOI//http://dx.doi.org/10.4314/gjds.v16i2.11
}

\begin{abstract}
This study explores the perspectives of relevant stakeholders on the engagement of West African migrants in retail trading businesses meant for indigenes under the Ghana Investment Promotion Centre Act. The study was conducted qualitatively on 13 participants in the Accra Metropolis (Which comprised immigrant key informants and institutional stakeholders) using semi-structured interview guide. Thematic analysis procedure was used to analyse the data and report the findings. The results showed that the immigrant interviewees were oblivious of the Ghana Investment Promotion Centre Act and so considered their retail businesses as legitimate under the Economic Community of West African States protocol on establishment. They further justified the legitimacy of their trading activities with the conviction that other Ghanaians are engaged in similar businesses in their countries of origin. Nevertheless, participants from the institutions unanimously dispelled the views shared by the immigrant interviewees and argued that the Ghana Investment Promotion Centre law supersedes the Economic Community of West African States protocol. They bemoaned that the immigrants' retail activities are not only a threat to indigenous businesses and revenue mobilisation, but have the proclivity to engender regional conflicts. The policy and security implications of this paper are elucidated in the discussion and conclusion sections.
\end{abstract}

Keywords: Ghana, Implications, Migrant Retail Trading, Stakeholder Perspective

\section{INTRODUCTION}

One major immigrant group in Ghana aside the Chinese, Koreans, Lebanese, Syrians among others, whose economic activities have over the years been a bone of contention, is the involvement of West African migrants in petty retail trading activities across the country (Baah, Otoo \& Ampratwurm, 2009; Obeng, 2015; 
Karibo, 2014). This phenomenon has been particularly exacerbated due to the complexities surrounding the legal and policy environments at the national and sub-regional levels (Ghana Statistical Service [GSS], 2012; Ajavon, 2014; Karibo, 2014). For instance, while at the sub-regional level, the Economic Community of West African States [ECOWAS] Protocol on free movement of persons, right of residence and establishment in 1979 mandated all member states to stop demanding visas and residence permits, and allow West Africans to undertake commercial activities within their territories (ECOWAS Commission, 2014), at the national level the Ghana Immigration Act (Act 573) and the Ghana Investment Promotion Centre (GIPC) law (Act 865) have set conditions for investment and other economic activities of immigrants in the country (Abdoulahi, 2005; GSS, 2013).

The GIPC law in general is an act to provide for the GIPC as the agency of Government responsible for the encouragement and promotion of investments in Ghana, to provide for the creation of an attractive incentive framework and a transparent, predictable and facilitating environment for investments in Ghana and other related matters. However, with respect to foreign investment, the investment law (GIPC Act) requires an immigrant to have a minimum liquidity of US\$1million to invest (Affrifa, 2004; Karibo, 2014). Although the investment laws of Ghana do not prohibit foreigners from investing in any aspect of the economy, the GIPC Act has specified economic activities that are wholly reserved for indigenes in Section 27 of the Act. According to this section, a person who is not a citizen shall not invest or participate in: the sale of goods or provision of services in a market, petty trading or hawking or selling of goods in a stall at any place (GSS, 2012; GIPC Act, 2013).

Since the promulgation of the GIPC law in 1994 and its subsequent revision in 2013, the debate on foreign participation in restricted business niches (petty retail trading activities) in the market area meant for Ghanaian traders raged on unabated (Obeng, 2015; Daily Graphic, 2017). The above phenomenon has generated much public discussion as to why immigrants despite the restrictions on the retail sector still continue to engage in these enterprises. While some policy analysts blamed the phenomenon on weak government institutions responsible for the implementation of the law (e.g. GIPC), others attributed the problem to the ratification of the ECOWAS treaty on establishment. Regrettably, in many of these discourses, issues concerning immigrants' knowledge about the GIPC Act and their perception about the legality of their petty retail activities are seldom considered as part of the broader challenges facing the enforcement of this investment law. The current development places Ghana on a cross-road on how the Act on foreign participation in petty retail trade could be thoroughly implemented. In line with this, the current study examines this debate based on analysis of data sourced from key informants 
(stakeholders) of four state institutions (Accra Metropolitan Assembly [AMA], Ghana Immigration Service [GIS], GIPC and Ghana Union of Traders Association [GUTA]) and nine leaders of West African immigrant retailers from the study area. The main objective of this study was to explore the views of these stakeholders regarding the legal, policy and security implications of the engagement of immigrants in retail businesses in the country. In this study, itinerant migrant traders/retailers describe immigrants who sell wares as they move along streets, road pavements, or office to office using different tools to support mobility (e.g. bicycles, motor cycles, hand cart, trolley-pushers or barrows) or immigrants who move and sell on foot (Yendaw, Tanle \& Kumikyereme, 2019).

To make the study more focused and easier to comprehend, it was guided by the following questions: do West African migrants in retail trading businesses have any knowledge about the GIPC Act? How do they perceive the legality of their retail businesses? What are the policy and security ramifications of their retail activities? And what are the challenges associated with the enforcement of the GIPC Act which debars immigrants from undertaking petty retail trading? Answers to these questions are pertinent because the itinerant retail activities of immigrants especially West African migrants raise critical policy issues, and have consequences for the development of Ghana and sub-regional security and peace. Hence, this study strives to offer responses to these questions raised here and to provide recommendations to shape public policy and offer policy alternatives to guide the implementation of the GIPC Act. The study is organised under six main sections: introduction, review of literature, study setting and methodology, results, discussion and conclusions and key policy implications.

\section{REVIEW OF LITERATURE}

This section of the study critically engages with the existing literature on regionalism, nationalism (protectionism) and integration within regional blocs. This is fundamental because the participation of immigrants in petty retail trade in Ghana invokes wider debates around regionalism and regional integration. The term regionalism has been generally explained as the efforts by a group of collaborating countries to enhance their economic, political, social, or cultural interactions (Lee, 2002; Sakyi \& Opoku, 2014). African Union [AU] (2009) and Bolaños (2016) also defined regional integration as a commercial policy of discriminatively reducing/eliminating protectionist economic policies among cooperating nations by widening their markets and moving toward common currency and price for goods and services. In such arrangements, De Melo and Tsikata (2014) submit that political actors are swayed to shift their loyalties, and political objectives toward a 
new centre, whose institutions possess or demand jurisdiction over the established national states.

The literature on regionalism and integration revealed that economic, political, and socio-cultural relationships in Africa have been changing rapidly in the last few decades (Sakyi \& Opoku, 2014). That is, there has been a significant upsurge in Regional Economic Communities [RECs] also known as Regional Trade Agreements [RTAs] since the early 1990s (Adepoju, 2002; De Melo \& Tsikata, 2014). For instance, Sakyi and Opoku (2014) and De Melo and Tsikata (2014) found that while NorthSouth RTAs was about sixty per cent of all RTAs, South-South RTAs was only twenty per cent. However, by 2010, it was noticed that while two-thirds of PTAs were of South-South origin only one-quarter were North-North oriented. In 2010, 58 African countries were involved in 55 RTAs, of which 43 were South-South and 12 were North-South (WTO, 2013). These changes in RTAs according to De Melo and Tsikata (2014) reflect an increasing involvement of African countries in regional integration in regional blocs.

In West Africa, regionalism and economic and political integration have their origins in the political forces influenced by the colonial legacy that resulted in a configuration of geographically artificial states where ethno-linguistic diversity and arbitrary borders contributed to high intra-regional trade relations (Alesina, Easterly \& Matuszeski, 2011; GSS, 2012). The consequence of the formation of these artificial borders is that immigrants in West Africa continue to regard the region as one huge economic unit within which trade in goods and services typically flow across countries (Yendaw et al., 2019). Thus, the persistent engagement of immigrants in retail businesses in Ghana could be explained by the creation of the ECOWAS protocol especially the treaty on establishment which seeks to facilitate intra-regional trade interractions among states (GSS, 2012).

The first period of regional integration began during the first decades of independence, and was articulated in the Lagos Plan of Action, an initiative of the Organisation for African Unity (now African Unity), adopted by the heads of states in 1980 (De Melo \& Tsikata, 2014). The proposed framework according to Sakyi and Opoku (2014) was for African integration into pan-African unity and continental industrialisation by the division of the continent into RECs known as the African Economic Community. Three regional integration arrangements were supported by the Economic Commission for Africa: Economic Community of West African States [ECOWAS], Common Market for Eastern and Southern Africa [COMESA], and the Economic Community for Central African States ECCAS], and later, the Arab Maghreb Union [AMU] (De Melo \& Tsikata, 2014). This early phase coincided with the heyday of central planning when speedier industrialisation was considered as 
a phenomenon that could only take place at regional levels under free trade among members (Alesina et al., 2011). However, leaders of these young post-independence African states were unenthusiastic to encourage the erosion of national sovereignty, which would have been necessary to co-ordinate and manage the affairs of the African union (De Melo \& Tsikata, 2014). Also, the diversity across Africa such as resource-rich and resource-poor countries translated into different interests that strengthened countries' insistence on the reverence for sovereignty and territorial integrity (GSS, 2012; De Melo \& Tsikata, 2014). Thus, commitment to regional integration and pan-Africanism was weakened and continue to be weak resulting in nebulousness and multitude of objectives, which helped states underrate the issues that divided them (Qobo, 2007).

In the 1980 s, and later, following the end of the cold war, initiatives entered a second, more outward-looking phase (De Melo \& Tsikata, 2014). According to Sakyi and Opoku (2014), most initiatives were a revival of previous efforts that had either been abandoned, such as the East African Community [EAC], or not implemented, such as the Common Market for Eastern and Southern Africa [COMESA], while others were new with significant membership overlap reflecting countries hedging their bets. This overlap of membership complicates the task of policy co-ordination and slows down attempts at deep integration as large membership made it difficult to delegate authority to regional bodies (Portugal-Perez \& Wilson, 2009). The lack of enthusiasm and commitment to regionalism in Africa has manifested itself in member countries developing their own national strategies, plans and priorities independently (Sakyi \& Opoku, 2014). Although African countries continue to speak of collective action for regional integration, no single state has yet designed its national plans to be consistent with the promotion of effective economic integration (De Melo \& Tsikata, 2014).

In West Africa, the ECOWAS was formed on 1975 to among other things encourage, foster and accelerate the economic and social development of member states in order to improve the living standards of their populations (ECOWAS Treaty, 1975). The recognition of the need for economic integration including free flow of persons, goods and services stimulated the promulgation of the ECOWAS Protocol on free movements, and the right of residence and establishment in 1979 (Abdoulahi, 2005; ECOWAS Report, 2006). The first and second phases of the Protocol guaranteed free entry of citizens and residence without visa for 90 days and that was ratified by all states in 1980. Yet, the third phase (right of establishment) has not been fully sanctioned by all states (Abdoulahi, 2005). As a result, many countries in West Africa including Ghana have instituted protectionist investment policies like the GIPC Act to protect their nationals against foreign competition. Besides, by 
Ghana Immigration law, immigrants cannot work except by a permit granted by the Immigrant Quota Committee (GIS, 2010). As stated in the introductory part of this study, the GIPC Act has also set US\$1million as the financial requirements for investment for immigrants. This minimum capital requirement is indeed a drawback to many West African migrants who want to invest (Affrifa, 2004; GSS, 2012). Consequently, most immigrants engage in retail businesses without permit and in so doing avoid the US\$1million financial obligations (GSS, 2012). The ECOWAS protocol on the free movement complicates this state of affairs as citizens enter the country on the free movement protocol and stay on to conduct their retail businesses without letting the authorities know (Affrifa, 2004; GSS, 2012). ECOWAS citizens are therefore able to side-step the immigration laws of the country.

\section{STUDY SETTING AND METHODOLOGY}

This study was undertaken in the Accra Metropolis [AM] in the Greater Accra Region. However, owing to the built-up nature of the metropolis, nine communities which are predominantly inhabited by West African migrant retail traders were purposively selected and used for the study (Figure 1). These communities were: Abeka, Ablekuma, Abossey Okai, Agbogbloshie, New Fadama, Lartebiokorshie, Sukura, Nima and Mamobi. The role of some of these communities as major dwelling places of West African migrant retailers has similarly been reported by other studies such as GSS (2014) and Yendaw, Tanle and Kumi-Kyereme (2019). AM was chosen for this study mainly because the 2010 Population and Housing Census [PHC] showed that over 21.0\% of ECOWAS nationals lived in the Greater Accra region [which is the highest compared to other regions in Ghana] and AM hosted the largest proportion of these immigrants (GSS, 2013, 2014). 


\section{Figure 1: Map of Accra Metropolis showing the study settings}

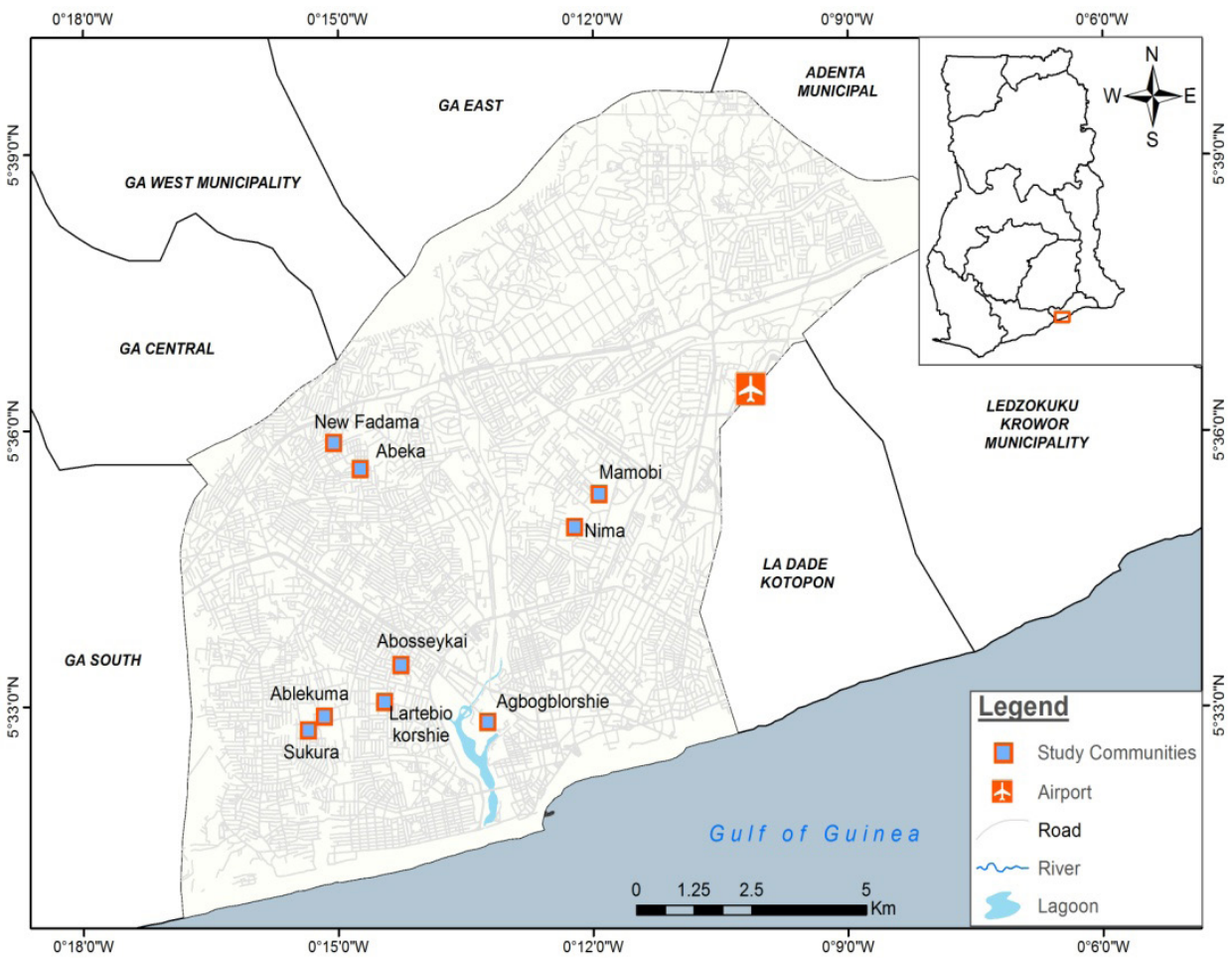

Source: GIS Unit of the Department of Geography and Regional Planning (2017)

The methodology used for this study was a qualitative approach, guided by phenomenology, which has traditionally relied on in-depth interviews to collect data (Lopez \& Willis, 2004). Phenomenology involves studying the lived human phenomena within the social contexts in which the phenomena occurred and from the perspectives of the participants (Sarantakos, 2005). The aim of phenomenology is to describe the meaning of a concept or phenomenon for several individuals who have experienced it (Creswell, 2007). With respect to this study, it explored the perspectives of relevant stakeholders on the participation of West African migrants in retail trading businesses meant for Ghanaian nationals under the GIPC Act and the policy and security implications therein.

In tandem with the research approach (qualitative), data for the study were mainly derived from in-depth interviews. A semi-structured guide was designed to facilitate the interview process. The guide comprised both open-ended questions and pre-scripted probes. As regards the time and location for the interviews, it was decided at the expediency of the interviewees by requesting them to choose where and when they needed the interviews to be carried out. Due to the busy work 
schedules of the interviewees, most of the interviews were conducted at home. The duration for each interview was between 30-45 minutes. The main issues captured in the data collection included background characteristics of the interviewees, knowledge about the GIPC Act, the legality of their retail businesses, implications of their retail activities and challenges associated with the implementation of the GIPC Act.

The study purposively selected 13 key informants (stakeholders) and solicited their viewpoints on the participation of West African migrants in itinerant petty retail trade and the policy and security ramifications of their activities on the development of the country and the sub-region. 13 interviewees were considered for this study due to saturation of responses on the topic under study. These interviewees comprised one stakeholder each of Accra Metropolitan Assembly [AMA], Ghana Immigration Service [GIS], Ghana Union of Traders Association [GUTA], and Ghana Investment Promotion Centre [GIPC]. These institutions were chosen for the study because they are legally mandated to regulate trading or investment activities of immigrants and non-immigrants in the country. The other nine interviewees were leaders of the immigrant retailers (one from each study community) who were responsible for the coordination of the retail trading activities of their countrymen. The main criteria for selecting the immigrant leaders were: one, the immigrant leader ought to have involved in petty retail trading for at least one year or more and two, he or she ought to have not been a dual national, naturalised citizen or a national by marriage. In terms of demographic profile, all the interviewees were males. While interviewees from the institutions attained tertiary education, their immigrant counterparts had no formal education. With the exception of three interviewees who were single, the remaining 10 were married. While the immigrants were Muslims, the institutional stakeholders were Christians which reinforced findings from GSS (2012) that most immigrants from the Sahelian region are Muslims.

A voice recorder was used to record the interviews complemented by note taking. Permission and/or consent was sought from the interviewees before their voices were recorded. The in-depth interview guide was administered by the researcher and four trained field assistants who could communicate in the languages spoken by the participants (English, French and Hausa). The actual data collection started on January $20^{\text {th }} 2017$ to $20^{\text {th }}$ February 2017. All protocols involving community entry were diligently observed with assembly members who served as focal persons throughout the fieldwork and helped the research team contact the immigrant leaders in the nine study sites (Figure 1). Ethical clearance with protocol 
number (UCCIRB/CHLS/2016/23) was obtained from the University of Cape Coast Institutional Review Board before the study began.

Data from the interviews were first validated (by playing and listening to the audio recordings several times) to ensure they were accurate and completed. Afterwards, it was realised that all the 13 audio recordings were complete, accurate and usable. Consequently, the data were manually processed and analysed using thematic analysis procedure. The thematic analysis technique was used to identify, analyse and report patterns from the interviews and this was guided by the study objectives. According to Dayour (2019), thematic analysis is a fundamental technique in the analysis and presentation of qualitative data mainly because it is flexible and does not restrict itself to any philosophical thought. The thematic analysis undertaken in this study modelled on the analysis approach proposed by Thomas (2006): data preparation and close reading of text to become familiar with the raw data; development of categories from the raw data into a model or framework (coding the data); searching for themes and recognising relationships (i.e. axial coding); and refining themes through coding consistency checks (e.g. independent parallel coding). The 'member check' approach (respondents' validation technique) was used to guarantee the credibility and validity of the results by contacting four interviewees to confirm the interview transcriptions and summaries. The results were anonymised of the interviewees; their names and residential locations were expunged from the results. Findings of this study are presented in the ensuing sections.

\section{RESULTS}

\section{Immigrants' Knowledge about the GIPC Act}

This empirical section of the study explores the views of stakeholders on whether or not West African migrant traders in retail business were aware of the existence and operation of the GIPC law which prohibits foreigners from engaging in any form of petty retail trading in Ghana. In understanding this, the opinions of both immigrant key informants and institutional stakeholders were sought on the issue. During the interviews with leaders of the immigrant traders, they were of the consensus that they had no knowledge of the GIPC Act which proscribes their retail trading activities in Ghana. They however made reference to the National Health Insurance Scheme, the ECOWAS protocol on free movement and establishment and voting during elections as the three issues they knew. The following expressions from two of the immigrant leaders from Burkina Faso and Togo demonstrate their obliviousness about the GIPC Act: 
Frankly, I do not know of any law on petty retail trading. I have not heard anything about this law from my embassy too. But I am aware that foreigners are not supposed to vote during elections in Ghana or enrol on the National Health Insurance Scheme [39-year old interviewee from Burkina Faso].

On the part of the Togolese immigrant leader, this was what he remarked:

"I have no idea of a law like that. The only regulation I heard about is the ECOWAS protocol on free movement of people and establishment of West Africans" [38-year old interviewee from Togo].

The above assertions by the immigrant leaders were however counteracted by stakeholders from some institutions. They intimated that as immigrants it is part of their responsibilities prior to their migration to obtain accurate information regarding the laws of the destination. In addition, they reported that the claim by the immigrants' leaders that they were not aware of the law was unjustifiable. In reacting to this, a 62-year old and 47-year old interviewees from GUTA and AMA respectively had this to say about the immigrant leaders' assertions:

The law is there and these immigrants know of it. Before migrating to Ghana, they were supposed to seek more information on Ghana's immigration and trading laws. Let me give you this example, if they were to travel to say the USA or UK would they have gotten there and violate their investment laws and then turn around to say they were not aware? Their claim cannot be true; besides ignorance of the law is no excuse.

\section{Legality of Retail Trading of West African Migrants}

Besides the Chinese, Lebanese and Syrian traders, West African migrant traders particularly Nigerians are often targeted by the GIPC and AMA task force against illegal retail trading (Debrah, 2007; Karibo, 2014). Ghanaian traders and entrepreneurs have constantly complaint of transgression of restriction for foreigners in retailing and the lack of respect for labour rights (Ajavon, 2014; Daily Graphic, 2017). The GUTA, which is a representation of Ghanaian retailers and petty traders have protested on a number of occasions against the alleged impunity of these perpetrators particularly itinerant immigrant traders and exerted political pressure on government to remove them from the market area (Obeng, 2015; Daily Graphic, 2017).

With this background, this section of the study strove to understand from the viewpoint of stakeholders (key informants) regarding the legality of West African 
immigrants' involvement in retail trading in the Accra Metropolis. When the four interviewees from the sampled institutions were requested during the in-depth interview to share their thoughts on the legality of the petty retail trading activities of West African migrants in the Accra Metropolis, they stated emphatically that their retail activities were unlawful and a gross violation of the GIPC Act (Act 865 of 2013). An example of such thoughts was expressed by a 43-year old interviewee from GIS:

In fact, from Ghana immigration point of view, Ghana is a sovereign state and thus most of these West African migrants engaged in petty retail trading are in contravention with the law of the GIPC Act which preserves retail trading businesses for indigenes.

As was expected, the interviewee from the GUTA who represented the Ghanaian competitors in the market area sounded heatedly over the whole matter and blamed successive governments in Ghana for failing on their duty to 'flush out' all foreign retailers in the market area. In the interviewee's own words, this was what was said:

Illegality is illegality, legality is legality. So, for any country that wants to develop, no matter how good your policies are if you are not able to monitor, evaluate and punish offenders like these itinerant immigrant traders when necessary, things will be difficult for you [62-year old interviewee from GUTA].

The responses obtained from the other two interviewees from the GIPC and AMA on the itinerant retail trading activities of West African migrants were at variance with what was reported by the representatives of GIS and GUTA. Though they admitted that their itinerant retail activities were illegitimate, a technical explanation on what the law proclaimed was immediately given which suggested that the itinerant trading activities of the immigrants cannot entirely be said to be an infraction of the GIPC Act on petty retail trading. These interviewees explained that those immigrants who are engaged in itinerant retail trading along streets or around offices and residential locations to sell their wares for example cannot be seen as violating the GIPC Act. They submitted that such itinerants undertake their business transactions outside the designated market spaces provided by the district assemblies. To them, it therefore becomes confusing to label their businesses as illegal under the current Act. During the interview with the interviewees, this was how they interprets the GIPC Act:

The GIPC law (Act 865) states that foreigners cannot do retail trading in the designated markets in the country. Those who want to do trading in the market area have to meet a threshold of 1 million dollars and use the 
same company to employ 20 Ghanaian at least. So those who trek around doing petty retail trading are not supposed to enter the designated markets and do their business. If these individuals are found, the law can deal with them. But the issue is that most of these West African migrants prefer moving around and selling on the streets, selling from house to house or from one office to the other. Note that these are outside the designated markets stipulated in the law. [59-year old interviewee from GIPC; 47-year old interviewee from AMA].

In a contrary view to what have been indicated by the interviewees of the institutions, the immigrant key informants were clear in their submission that their trading activities were not illegitimate, citing the ECOWAS protocol to buttress their views. They noted that they were ECOWAS nationals, and since the government of Ghana is a signatory to the body's treaty which provides that all West Africans under ECOWAS have the right of residence and establishment, they had the right to carry on their retail trading activities unimpeded once the activity does not involve the sale of contraband goods. The immigrant key informants further remarked that other Ghanaian nationals are also into similar retail activities in their home countries. These views were espoused in the following narrations by two of the immigrant leaders from Burkina Faso and Niger:

If you go to my country (Burkina Faso) or even Togo right now, there are thousands of Ghanaians doing similar businesses there. We are all under the ECOWAS treaty which allows us all to move freely to do businesses anywhere within West Africa. Seriously, for me I am not aware my trading activities are illegal. Yes, some Ghanaian competitors occasionally harass me in my business transactions claiming that my activities violate the law. But I disagree with them. I will never go against the laws of Ghana [39-year old interviewee from Burkina Faso]. I don't think my business is illegal because I do not sell illicit drugs or contraband goods. [45-year old interviewee from Niger].

The above views by the immigrant key informants that their trading activities were lawful and sanctioned by ECOWAS protocol was dispelled by representative of the GIPC and AMA, but quickly repeated again that there was the need to handle the issues regarding the immigrant traders with caution, arguing that the phenomenon has political and economic repercussions for the sub-region. This assertion is detailed in this excerpt:

The GIPC Act supersedes the ECOWAS protocol because even the protocol has not been fully implemented now. Moreover, the protocol does not 
cancel national regulations. But these issues are dicey because if as a country we don't handle it well, it will have economic and political repercussions within the sub-region [59-year old interviewee from GIPC; 47-year old interviewee from AMA].

The above view was reinforced by another interviewee from the GUTA who noted that:

I think people are using the ECOWAS protocol as a flimsy excuse. Ghana is a sovereign country and we have our laws. ECOWAS is not integrated into every country. We don't have a common investment law. So, nobody has the right to use ECOWAS as an excuse. Our country's law should supersede any protocol, so I don't think the ECOWAS protocol is having any effect on the GIPC Act [62-year old interviewee from GUTA].

\section{Implications of West African Migrants' in Retail Trading}

Studies have consistently shown that the engagement of foreigners in retail trading in Ghana constitute a serious threat to the survival of Ghanaian owned businesses (Baah et al., 2009; GSS, 2013). Ghanaian retail traders who are members of GUTA are the most critical of the trading activities of foreign migrants. GUTA has continually kicked against the dumping of the market with cheap counterfeit goods from duty free importing countries such as Togo and Burkina Faso, the transfer of investment in manufacturing into trading companies contrary to the GIPC law (Daily Graphic Reports, 2017). They also accused the immigrant traders of unfair competition and trading in fields for which they were not qualified. Consequently, this section of the study elicited the views of institutional stakeholders on the implications of the retail trading activities West African migrants in the country.

To start with, an analysis of the responses generated from the interviewees revealed negative reservations with respect to the retail activities of the immigrant traders in the study area. Similar to what has been observed in the literature, the interviewees were of the opinion that not only do the immigrant retail traders evade taxes to the state due to the lack of data on them and the mobile nature of their business transactions, but they also introduce unhealthy competition between them and Ghanaian retailers. In explaining the consequences of the immigrants' engagement in retail trading in the study area, the interviewee from the GIPC had this to say:

I think it is the competition that is the challenge. That is why the Ghanaians within the retail trading sector always complain that foreigners have taken over their jobs. Worse of its all, some of the Ghanaian traders don't have the capital for businesses competition. 
In terms of the effect of their activities on the economy, most of those migrants do not pay taxes to the state due to the lack of data on their trading activities and that affect revenue mobilisation greatly. [59-year old interviewee from GIPC].

In buttressing the above observation, the interviewee from AMA and GUTA expressed that:

The retail trading activities of West African migrants throw many Ghanaian traders out of business by selling substandard products at lower prices [47-year old interviewee from AMA; 62-year old interviewee from GUTA].

\section{Challenges with the Enforcement of the GIPC Act}

In this section, data regarding the challenges associated with the implementation of the GIPC law were solicited from interviewees of the four institutions engaged for the study who are responsible for enforcing the GIPC Act. During the interview, the interviewees stated that absence of reliable data on the retail activities of immigrants and lack of harmonization between the GIPC Act and that of the ECOWAS protocol on establishment were key impediments on the smooth implementation of the GIPC law. They further bemoaned the attitude of some Ghanaians noting that they help shield the retail activities of immigrants followed by corruption among state agencies. In elucidating the constraints they face with the enforcement of the Act, two stakeholders from GIS and AMA made these revelations:

It seems the GIPC law conflicts with the ECOWAS protocol. Sometimes the GIPC law is overlooked due to fears of destroying diplomatic relationships with other countries. Moreover, some Ghanaians front for these migrants by shielding them from the law. Another challenge is that there is no accurate statistics on these itinerant migrant traders. And so, information on them is scanty, making it difficult to track them in order to come out with definite figures that will help us monitor their retail activities [43-year interviewee from GIS; 47-year interviewee from AMA].

For the key informant from GUTA, the inability of government to put into force the GIPC Act was blamed on corruption in government agencies. In an attempt to clarify the issue, the interviewee retorted in this manner:

The point is, one cannot even understand why the Act cannot be implemented. This tells you there is a big question mark there. For me, I 
attribute this whole thing to corruption in the government agencies [62year old interviewee from GUTA].

In addition to these challenges enumerated, deliberations with the interviewee from GIPC provided a further context to the whole saga. He lamented over the difficulties entailed in identifying who a West African immigrant is and the historical antecedents behind the presence of some of the immigrant retailers in Ghana. In discussing the challenges pertained to the implementation of the GIPC Act, this was what he said:

In the ancient times some Ghanaian grandparents brought some of these migrants' descendants onto their farms to work for them. Some of them got married to Ghanaians and gave birth and their children have gone back to marry in their home countries and have returned to settle in Ghana. So, the issue of integration is important. Even though I admit their petty retail activities are illegal, as a country we need to be careful of how we deal with them [59-year old interviewee from GIPC].

\section{DISCUSSION}

This study explores the perspectives of relevant stakeholders on the participation of West African immigrants in petty retail businesses in Ghana and the policy and security implications associated with their business operations. Findings from the study revealed that West African migrant retail traders have no knowledge about the GIPC Act. This evidence was confirmed in the responses gathered from the immigrant key informants. The immigrants' lack of knowledge about this Act probably might have accounted for their engagement in this protected business niche (petty retail trade). This finding supports what Affrifa (2004), GIS (2010), GSS (2012) and Karibo (2014) indicated that many ECOWAS nationals reside in Ghana beyond the 90 days' permit and undertake their retail businesses without regularising their activities under the work and residence permit requirement of Ghana immigration law and the GIPC Act. This phenomenon could be explained by the fact that most West African migrant retailers are uneducated (GSS, 2012) which might have affected their understanding of Ghana's investment laws.

It was found in the study that whereas the immigrant key informants considered the retail trading activities of West African migrants as lawful and in conformity with the ECOWAS protocol on establishment and that other Ghanaians are into similar retail businesses at their areas of origin, the stakeholders from the institutions disagreed stating that Ghana is a sovereign country and that the GIPC Act supersedes the ECOWAS protocol. They also stated that the ECOWAS protocol 
has not been fully implemented across countries which confirms the claim made by Abdoulahi (2005) and Karibo (2014) that the third phase of the ECOWAS protocol (right of establishment) is yet to be enforced. These observations further corroborate what have been alluded to by other authors (Baah et al., 2009; GIS, 2010; Sakyi \& Opoku, 2014) that the provisions of the ECOWAS protocol conflict with country specific laws which reserved certain trading activities for locals. These findings also support what Qobo (2007) has noted that the great diversity across Africa such as disparity in resource endowments continue to translate into different national interests resulting in many countries insisting on sovereignty. The current exposé equally concurs with what De Melo and Tsikata (2014) noted that no single state has yet designed its national plans to conform with the ECOWAS protocol on establishment which seeks to promote regional economic integration.

Although interviewees from GIPC and AMA acknowledged that the petty retail transactions of West African migrants are in contravention of the GIPC Act, a technical interpretation of the Act was given. They suggested that immigrants who are engaged in itinerant retail trading cannot on the surface be exclusively described as illegal under the current GIPC Act. According to them, the GIPC Act only prohibits the entry of foreign petty traders in designated market spaces by district assemblies. They therefore argued that immigrant traders who transact their trading activities outside the designated market areas such as street trading can be very confusing and difficult to pigeonhole as illegal. The current revelation by these interviewees suggests that the GIPC Act has inherent loopholes and would require a proper interpretation and understanding across the relevant stakeholders to avoid ambiguities and potential conflicts on what the law entails.

The study revealed that the involvement of immigrants in retail trading in Ghana has adversative consequences on indigenous businesses and revenue mobilisation. Findings from the stakeholders of the four institutions showed that most immigrant retailers evade taxes and disrupt the business activities of indigenes through excessive competition. The non-payment of taxes according to the interviewees is due to the lack of accurate statistics on the trading activities of immigrants. These evidences reinforce what Bromley (2000) and GSS $(2012,2014)$ stated that informal street trading is linked with tax evasion. These findings also underscore the observation made by GIS (2010) and GSS (2013) that many West Africans enter the country surreptitiously and fraudulently by means of false documents or legally through a temporary visa or permit followed by those who have over stayed their permits. The above findings equally confirm what Daily Graphic reports (2017) and Obeng (2015) had indicated that the involvement of immigrants in petty retail sector constitute a serious threat to the survival of locally 
owned businesses. This evidence further concurs with what Baah et al. (2009) found in a survey of Chinese investment in Ghana, who attributed the loss of livelihoods to cheap Chinese imports that often out-compete locally made substitutes. These qualitative revelations also justify what Olsen (2011) said that the activities of immigrant traders in Ghana raise new policy issues and that their activities have consequences for the development of Ghana and thus called for a coherent policy action to deal with it head on.

In spite of the perceived negative consequences associated with the immigrants in the petty retail sector coupled with the fact that their activities are unlawful in the context of the GIPC Act, the participants from the law implementing agencies (GIS, GIPC, AMA \& GUTA) cited a number of factors which act as bottlenecks against the smooth implementation of the GIPC Act which seeks to sanitise the system of foreign retailers. The challenges outline during an interview with them ranged from lack of statistics on mmigrants for proper coordination and monitoring to difficulties related to the absence of harmonization between the ECOWAS protocol and the GIPC Act. Negative attitudes of some Ghanaians who conceal the retail activities of foreigners were also enumerated as major hurdles which derail their efforts in implementing the GIPC law to the latter. These revelations are congruent with the observation made by GSS (2012) and Obeng (2015) that lack of statistics on immigrants and poor enforcement of Ghana's immigration laws continue to hamper proper coordination of the economic activities of foreign nationals in Ghana.

\section{CONCLUSIONS AND KEY POLICY IMPLICATIONS}

Based on the major findings obtained, the following conclusions and implications are drawn from the study. While the engagement of West African migrants in small scale trading activities were viewed by stakeholders of GIPC, AMA, GIS and GUTA as illegal under the GIPC Act, the study notes that the immigrant key informants were oblivious of the aforementioned Act. The petty retail business activities of West African migrants were also perceived by interviewees of the institutions as a threat to local businesses and national revenue mobilisation efforts which could be situated within the broader literature around nationalism where many countries tend to pursue protectionist economic agendas and perceive regional cohesion as a threat to sovereignty, territorial integrity and economic development. Nevertheless, enforcement of the GIPC Act was described by the institutional stakeholders as challenging owing to lack of statistics on West African migrants, concealment of their petty retail activities by some unscrupulous Ghanaians and lack of harmonization between the ECOWAS protocol and the GIPC Act. 
It emerged that most West African migrant retailers are ignorant of the GIPC Act and so considered their itinerant retail trading activities as legitimate. On the basis of this, it would serve well for the government of Ghana through the GIPC to as a matter of earnestness to roll out well packaged educational programmes to provide sufficient information on the GIPC law (Act 865) for all immigrant traders in Ghana. These educational programmes could include encouraging immigrant traders to consider pooling their financial resources together to form partnerships in order to satisfy the GIPC Act (Act 865) minimum financial requirement for foreign investors who wish to do business in the country. These educational programmes if well executed would help address the immigrants' lack of knowledge about the GIPC Act and deepen their understanding regarding the illegality of their retail businesses. One policy option the GIPC could however, consider is to begin to think of engaging relevant stakeholders such as GUTA, AMA, GIS, leaders of immigrant traders among others to have a reappraisal of the GIPC Act within the context of the ECOWAS protocol on establishment to see how the trading activities of the immigrants particularly those involved in itinerant retailing of goods could be incorporated into the government agenda of formalising the informal sector by creating reliable statistics on them. This would enable coordination of their activities and to ensure the immigrants fulfil their tax obligations. These measures would help provide an antidote to concerns raised by Ghanaian traders that the petty trading activities of immigrants engender unfair and excessive competition. These measures are worth considering because as revealed in the study, there are other Ghanaians engaged in similar retail businesses in other West African countries. Hence, any attempt to try to eliminate the immigrant traders from the market area could have detrimental effects on Ghana trade and diplomatic relations with other sister ECOWAS states and this could trigger reprisal attacks on Ghanaian nationals in other West African countries as history clearly shows such reprisal attacks.

From the in-depth interviews carried out with interviewees of GIS, GIPC, AMA and GUTA, it emerged that West African itinerant migrant traders constantly evade the tax net and their activities tend to disrupt the growth of indigenous businesses. This claim was similarly reported by the Daily Graphic in 2017 that the trading activities of immigrants constitute a threat to the survival of locally established businesses. Nevertheless, in order to obtain adequate empirical evidence to confirm some of these assertions, this study recommends for detail empirical inquisition nationwide on the impact of the retail trading activities of immigrants on local businesses and the economy as a whole. Studies of this nature are needed since such evidence could inform government on the way forward regarding the retail trading activities of immigrants in general. 


\section{ACKNOWLEDGEMENTS}

I am very grateful to Prof. Augustine Tanle and Prof. Akwasi Kumikyereme, who contributed to the design of this study. I also appreciate the effort made by all field assistants, opinion leaders as well as the key informants in the study communities who out of their busy schedules made this research work a success by paving the way for the research work to be carried out without a hitch.

\section{References}

Abdoulahi, M. (2005). Progress report on regional integration efforts in Africa towards the promotion of intra-African trade. African Trade Centre, Economic Commission for Africa.

Adepoju, A. (2002). Fostering Free Movement of Persons in West Africa: Achievements, Constraints, and Prospects for Intraregional Migration. International Migration, 40(2), pp. 3-28.

Affrifa, A. (2004). Poverty and the Ghanaian Family. Institute of African Studies. Research Review, 5, pp. 93-99.

African Union-New Partnership for Africa's Development [AU/NEPAD] (2009). Advancing Regional and Continental Integration in Africa. AU/NEPAD African Action Plan 2010-2015. Addis Ababa: AU/NEPAD.

Ajavon, J. (2014). Trading Activities of Chinese Migrants in the Central Business District ( $C B D$ ) of Accra. Unpublished Thesis Submitted to The School of Graduate Studies, University of Ghana, Legon, in Partial Fulfilment of the Requirements for the Award of a Master of Arts Degree in Migration Studies.

Alesina, A., Easterly, W. and Matuszeski, J. (2011). Artificial States. Journal of the European Economic Association, 9(2), pp. 246-77.

Baah, A.Y., Otoo, K.N., and Ampratwurm, E.F. (2009). Chinese investment in Africa: A Labour Perspective. Windhoek: African Labour Research Network.

Bolaños, A.B. (3016). A step further in the theory of regional integration: A look at the Unasur's integration strategy. France: GATE LYON SANTE-ETIENNE. https:// halshs.archives-ouvertes.fr/halshs-01315692.

Bromley, R. (200o). Street Vending and Public Policy: A Global Review. International Journal of Sociology and Social Policy, 20(1-2), pp. 1-29.

Creswell, J.W. (2007). Qualitative enquiry and research design: Choosing among five approaches. USA: Sage publications Ltd. 
Daily Graphic (2017). Drive Foreigners Out of Retail Markets. Accra: Daily Graphic, $28^{\text {th }}$ October, 2017.

Dayour, F. (2019). Backpackers' Experiences with Smartphone Usage in Ghana, Anatolia, Doi: 1080/13032917.2019.1597741.

Debrah, Y.A. (2007). Promoting the informal sector as a source of gainful employment in developing countries: insights from Ghana. The International Journal of Human Resource Management, 18(6), pp. 1063-1084.

De Melo, J. and Tsikata, Y (2014). Regional integration in Africa: Challenges and prospects. WIDER Working Paper, No. 2014/o37, The United Nations University World Institute for Development Economics Research (UNU-WIDER), Helsinki.

ECOWAS Commission (2014). Promoting Labour Mobility through Regional Cooperation: The case of ECOWAS. Workshop on Strengthening the collection and use of international migration data for development, Addis, November 18-22, 2014.

ECOWAS Community Treaty, 1975.

ECOWAS (2006). Status of Ratification of the ECOWAS Revised Treaty, Protocols and Conventions as at 28 March, 2007. Abuja: ECOWAS Commission.

Ghana Statistical Service [GSS] (2012). Population and Housing Census: Summary report of final results. Ghana Statistical Services, Accra: Ghana.

GSS (2013). 2010 Population and Housing Census Report: National Analytical Report. Accra, Ghana: GSS.

GSS (2014). 2010 Population and Housing Census: District Analytical Report. Accra Metropolitan, Accra: GSS.

Ghana Immigration Act, 2000 (ACT 573), Accra, Ghana.

Ghana Immigration Service-GIS (2010). Annual Report, Retrieved from http://www. ghanaimmigration.org/.

Ghana Investment Promotion Centre (2013). GIPCAct 865, Act, 1994 (Act 478). Retrieved from www.ghanapublishingcompany.com

Olsen, A.S.W. (2011). Reconsidering West African Migration: Changing focus from European immigration to intra-regional flows. Denmark, Copenhagen: DIIS Working Paper.

Karibo, Q.G (2014). The ECOWAS Trade Liberalization Scheme and the Ghana Investment Promotion Centre Act 478: Ghana-Nigeria Trade Wars. Unpublished Dissertation Submitted to The University of Ghana, Legon, In Partial Fulfilment of the Requirements for The Award of the Master of Arts Degree in International Affairs. 
Lee, M. (2002). Regionalism in Africa: A Part of Problem or a Part of Solution. Polis/ R.C.S.P./

C.P.S.R. 9, Numéro Spécial.

Obeng, M.K.M. (2015). Motivations, Network and Strategies of Ghanaian Importers of Chinese Products. Legon Journal of Sociology, 5(2), pp. 59-81.

Qobo, M. (2007). The challenges of regional integration in Africa in the context of globalisation and the prospects for a United States of Africa, ISS Paper 145 • June 2007 Price: R15.00

Portugal-Perez, A. and Wilson, J. (2009). Why Trade Facilitation Matters to Africa. World Trade Review, 8(3), pp. 379-416.

Sakyi, D. and Opoku, E.E.O. (2014). Regionalism and Economic Integration in Africa: A Conceptual and Theoretical Perspective. The African Capacity Building Foundation Occasional Paper 22 - 2014, Produced by the Knowledge and Learning Department, The African Capacity Building Foundation.

Sarantakos, S. (2005). Social Research. (4th Edition). New York: Palgrave Macmillan.

Thomas, D. (2006). A General Inductive Approach for Analyzing Qualitative Evaluation Data. American Journal of Evaluation, 27(2), pp. 237-246.

World Trade Organization (WTO). (2013a). Regional Trade Agreements. WTO, Available at: http://www.wto.org/english/tratop_e/region_e/region_e.htm. (Accessed June 29, 2019).

Yendaw, E., Tanle, A. and Kumi-Kyereme, A. (2019). Analysis of livelihood activity amongst itinerant West African migrant traders in the Accra metropolitan area. Journal of Global Entrepreneurship Research, 9(11), pp. 1-21. 